\title{
Antecedents of Knowledge Sharing Behaviour in the Public Sector
}

\author{
Everest Turyahikayo ${ }^{1}$, Venitha Pillay ${ }^{2}$ and Mary B. Muhenda ${ }^{3}$ \\ ${ }^{1}$ Law Development Centre, Uganda \\ ${ }^{2}$ University of Pretoria, South Africa \\ ${ }^{3}$ Uganda Management Institute, Uganda \\ turyahikayoeverest@gmail.com
}

\begin{abstract}
This qualitative study investigated antecedents of knowledge sharing in the public sector. Basing on the theory of planned behaviour and literature review, three antecedents guided the conceptualization of the study namely; employee attitudes, subjective or social norms and perceived behaviour control. Data from the 19 in-depth interviews were thematically analyzed. Findings revealed that employee attitudes towards knowledge sharing in the public sector were both positive and negative. While the theory of planned behaviour focuses on the attitudes of knowledge givers, it emerged that the knowledge seekers' attitudes mattered as well. Subjective norms were prevalent in meetings, teams, job rotation as well as in the Communities of Practice (CoP). The finding that Communities of Practice were disconnected in terms of knowledge sharing emerged surprising because we had not envisaged it since previous studies have not investigated it. Perceived behaviour control was modified by scanty organizational resources as well as incentives and policies. The study proposes knowledge sharing model for both practitioners and researchers.
\end{abstract}

Keywords: Knowledge sharing, attitudes, subjective norms, perceived behaviour control, Community of Practice

\section{Introduction}

Knowledge sharing is conceptualised as the process of accessing knowledge for application in solving work related problems (Christensen, 2007). Knowledge sharing relates to the provision of task related skills, experiences, abilities and expertise to help workers solve problems, develop new ideas, or implement policies or procedures (Wang and Noe, 2010; OECD, 2015).

Although the public sector is endowed with the knowledge resource (Cong and Pandya, 2003; Turyahikayo, 2018; Davenport and Prusak, 1998), evidence shows that such knowledge is not adequately shared to enhance decision making, solving of task related problems and improved service delivery (Caruso, 2017; Wamitu, 2016; Furlich, 2016). While we acknowledge the fact that knowledge should be shared so as to be meaningful (Oghavvemi, Sharabati, Paramanathan and Rahin, 2017; Kalani and Kamrani, 2017) it is noted that previous studies have not investigated fully the antecedents of knowledge sharing behaviour in the public sector. There are limited studies regarding the antecedents of knowledge sharing behaviour within the sector. A few quantitative studies have focused on knowledge sharing practices in the public sector organisations (Amayah 2013; Parka, et al, 2014; Sensuse, Cahyaningsih and Wibowo, 2015; Aerts and Haezendonck, 2017). There are a few, if any, qualitative studies focusing on the antecedents of knowledge sharing behaviour in the public sector. Consequently, the absence of qualitative studies has, to some extent, hindered the emergence of new knowledge regarding the factors that drive knowledge sharing behaviour in the sector. Yet, without understanding the antecedents of knowledge sharing behaviour in the public sector, we cannot satisfactorily propose appropriate knowledge sharing strategies for the sector. The current qualitative study addresses this gap by examining antecedents of knowledge sharing behaviour in the public sector using the theory of planned behaviour. The research question addressed in this study is; What are the antecedents of knowledge sharing behaviour in the public sector? The purpose of this qualitative study is to attempt to seek answers to the research question.

\section{Theoretical framework and Literature Review}

Previous studies have indicated that knowledge sharing largely depends on individual behaviour (Kuo and Young, 2008) driven by attitudes towards behaviour, subjective norms, perceived behavioral control (Punniyamoorthy and Asumptha, 2019) and intentions (Wang and Noe, 2010). These antecedents of knowledge sharing behaviour are conceptualized in Ajzen's (1985) theory of planned behaviour.

The Theory of Planned Behaviour (TPB) was propounded by Ajzen, (1985) who assumed that the intention to behave in a certain manner results from; a) an individuals' attitude towards the behaviour, b) their subjective norms, c) and perceived behavioural control over the outcome. Attitudes defined as the disposition to respond favourably or unfavourably to the self, others, and environment in relation to their intentions (Hwang, 2012; 
Yean, Johari and Sukery, 2015) can be strong or weak depending on the degree of importance attached to it (Howe and Krosnick, 2017). Such a degree of importance is influenced by personal values, interests and beliefs (Safa and Solms, 2016). Subjective norms are postulated as the outcome of cognitive structures such as perceived consequences of the behaviour and normative structures, like perceived approval by others (Hwang, 2012). Perceived Behaviour Control (PBC) is the individuals' belief about their ability to exhibit certain behaviours (Kuo and Young, 2008; Yean, Johari and Sukery, 2015). While the TPB focuses on nature rather than nurture driven factors, its wide usage in related studies make it suitable for this study.

\subsection{Literature Review}

In this section, we thematically discuss previous studies relating to antecedents of knowledge sharing behaviour in the public sector. The discussion is hinged on the theory of planned behaviour examined in the previous section.

\subsubsection{Attitudes Towards Knowledge Sharing Behaviour in the Public Sector}

Previous researchers have defined 'attitude' as a disposition to respond favorably or unfavorably to the self, others, and environment in relation to their intentions (Hwang, 2012; Yean, Johari and Sukery, 2015). Such a disposition towards behaviour can be strong or weak depending on the degree of importance attached to it (Howe and Krosnick, 2017). Such a degree of importance is influenced by personal values, interests and beliefs (Safa and Solms, 2016). An individual's attitude towards knowledge sharing will influence the behaviour to share. If one derives happiness in sharing his expertise, skills and know-how, he/she will share and it would appear, the reverse is true (Punniyamoorthy and Asumptha, 2019). Public sector employees who value their contribution to the organization or who feel that their contribution is valued by others are likely to develop strong attitudes to share their knowledge (Safa and Solms, 2016).

Scholars have further revealed more factors that shape employees' attitude towards knowledge sharing behaviour in the public sector. According to Wang and Noe (2010), if public sector employees have high capacity to absorb the knowledge that has been shared, people feel motivated to share more knowledge with them. Yet in some situations, public sector employees may have negative attitudes to share knowledge if they are worried of being misunderstood, or if they feel that their knowledge will not be used adequately (Zhang and Fai $\mathrm{Ng}$, 2012). Literature does not examine the circumstances under what the shared knowledge is likely to be taken out of context. It is also not clear when misunderstandings relating to the knowledge shared are likely to arise. Some scholars have indicated that even when there is enough absorptive capacity, seekers and givers of knowledge may have arrogant behaviours which hinder inter-personal collaborations for knowledge sharing (Hew and Hara, 2007). Hence, managers should facilitate employees to share knowledge (Yang, 2008).

\subsubsection{Subjective Norms and Knowledge Sharing Behaviour in the Public Sector}

The TPB conceptualizes subjective norms as perceptions of social pressures relating to performing behaviour (Ajzen, 1991). Subjective norms relate to an employee's perception of colleagues' views about the suggested behaviour (Yean, Johari and Sukery, 2015). These norms are reflected in the expectations of managers regarding an individual's sharing behaviour, proceeded by intentions (Hwang, 2012). If a public sector employee believes that fellow workers approve or disapprove sharing certain type of knowledge, he/she is likely to decide whether to share or not. Yet, the extent to which social norms prevail in the public sector and how this prevalence relates to knowledge sharing behaviour is not clearly articulated in the previous studies. Although Yean, Johari and Sukery (2015) contend that such norms put pressure on an individual to perform a particular behaviour, the same norms may force an employee to consider abandoning the planned behaviour (Safa and Solms, 2016). In the public sector, it is assumed that social norms are entrenched in the hierarchical ladders of seniority. Yet, we cannot tell from the literature which source of social norms impose pressure on employees to share or not to share knowledge. Do social norms from below pressurise top managers to share knowledge? Is the reverse true?

Previous research has further indicated that public sector employees have a role to manage subjective norms. Much as the norms held in groups impose pressure on an individual's sharing behaviour, personal preferences play a role in deciding whether to share or not. The choice still lies in hands of the knowledge giver (Nguyen, Nham and Hoang, 2019). Public sector employees are likely to share knowledge with colleagues who will reciprocate (Wang and Noe, 2010), a situation of 'I scratch your back, and you scratch mine too'. This is the case regardless of the prevailing subjective norms. Moreover, as employees interact more often so do the chains of subjective norms tend to weaken (Amayah, 2013). In this case, reciprocity is seen as the only way employees 
who share knowledge will cause others to share. Yet, reciprocity may not be sufficient without the backup of a knowledge sharing culture.

\subsubsection{Perceived Behaviour Control and Knowledge Sharing in the Public Sector}

Perceived Behaviour Control (PBC) has been conceptualized as the individuals' belief about their ability to exhibit certain behaviours (Kuo and Young, 2008; Yean, Johari and Sukery, 2015). If public sector employees believe that they have sufficient ability and resources, they will likely share their knowledge. If they feel resources for knowledge sharing are unavailable, the sharing behaviour will diminish (Chen, Chen and Kinshuk, 2009; Punniyamoorthy and Asumptha, 2019). Under the PBC, public sector employees make judgements regarding their ability to predict the planned behaviour. If workers believe their PBC over knowledge sharing is high compared to risks involved, the intention to share increases (Hajli and Lin, 2016).

Previous studies have indicated that a number of factors transcend resources in the control of behaviour for knowledge sharing. Scholars such as Wang and Noe (2010) have indicated that supervisor's control over employee behaviour was a significant predictor of an employee effort towards knowledge sharing. Yet, there is another body of literature painting a different picture. Scholars such as Liu and DeFrank (2013) demonstrated that self-interest, power and status affected knowledge sharing intentions even when the resources and incentives were in place. In other words, PBC on its own could not determine knowledge sharing intentions. From the foregoing, we can infer that previous studies have not adequately examined antecedents of knowledge sharing behaviour in the public sector. The current study attempts to address the existing knowledge gap.

\section{Research Methodology and Design}

In this exploratory study, three public sector institutions were requested in writing to participate in the study which request was granted. The three institutions were; Ministry of Public Service, Ministry of Education and Sports and Ministry of Justice and Constitutional Affairs in Uganda. The selected ministries were knowledge intensive with interconnected functions. The Ministry of Public Service had an overall mandate to guide performance management practices in the other two ministries. Yet, the laws enacted by parliament with guidance of the Ministry of Justice impacted on the ministries of Public Service and Education. While the three ministries were not the only knowledge intensive ones, with interconnected functions, their selection made the study feasible within the resource constraints. The individual worker was treated as the unit of analysis since subjective and personal insights were key for this study rather than group perspectives. Purposive sampling was used to identify and select 19 key informants (Creswell, 2014) in line with a similar design by Petty, Jarvis and Thomas (2018). The informants had rich information regarding the antecedents of knowledge sharing in the public sector. The key informants who were senior managers at the level of Heads of department were requested to give informed consent prior to the study. Semi-structured interviews were conducted in the informants' offices in order to elicit their perceptions in a natural setting (Hew and Hara, 2007; Yin, 2011). Perceptions were captured using field notes technique because it is more superior to any other technique (Halcomb and Davidson, 2006) in generating qualitative data (Castleberry and Nolen, 2018). The interview process ended after saturation in which case no new additional useful data emerged to constitute a conceptual category (Francis, et al, 2010). In order to enhance conformability and credibility three more interviews in addition to the 19 were conducted. In addition, three key informants were interviewed twice so as to guarantee response consistencies as advised by Aldiabat and Navenec (2018).

We applied thematic analysis technique in order to reduce data into workable themes and the emerging conclusions (Halcomb and Davidson, 2006). We took the advice from Halcomb and Davidson (2006) to the effect that researchers should code their own data since they are much more involved in the interview process. Mindful of the fact that text as data is often difficult to break into categories and themes (Castleberry and Nolen, 2018), we kept coding and re-coding as we identified codes, categories and themes in moving back and forth fashion (Erlingsson and Brysiewicz, 2017). We discarded codes reported by one informant purposely to avoid occasional incidence (Zhang and Fai Ng, 2012). We identified a number of inductive themes emerging a posteriori. Such themes included, employee attitudes; subjective norms and perceived behaviour control. The themes related closely to the constructs discussed in the theoretical framework and in the literature review. We interpreted and discussed the findings basing on the emerging themes as guided by Clarke (2009). An attempt was made to dig deep into the lived experiences of interviewees to understand the real meaning attached to the antecedents of knowledge sharing behaviour in the public sector. 


\section{Findings relating to Antecedents of Knowledge Sharing in the Public Sector}

The discussion below highlights key findings from the study relating to the antecedents of knowledge sharing behaviour in the public sector. The discussion is organised around three themes that emerged during the coding process. To recapitulate, the themes are; employee attitude to share knowledge, subjective norms and perceived behavioural control.

\subsection{Attitude towards Knowledge Sharing Behaviour in the Public Sector}

Informants were asked to indicate their attitude towards knowledge with colleagues; and whether colleagues shared knowledge with them. The study revealed a number of positive attitudes towards knowledge sharing behaviour. More than half the number of interviewees indicated that they willingly shared knowledge. "I share my knowledge with colleagues during formal and informal meetings". When asked when they shared their knowledge, they further stated; "I share knowledge during departmental planning, and when undertaking task accomplishments". Knowledge sharing behaviour was triggered by knowledge seekers. Some informants reported that quite often they sought knowledge from their peers and supervisors before, during and after task performance. There were also instances when workers had to seek clarifications on why certain activities had to be performed. While most informants reported good reception from colleagues they contacted for knowledge, there were some employees who harboured negative attitudes towards knowledge sharing. In support of this, four of the nineteen interviewees reported knowledge hoarding behaviour. "Some employees are not willing to share their knowledge. They think that hoarding knowledge makes them powerful and gives them a comparative advantage over their colleagues". This could testify to the prevalence of negative attitude towards knowledge sharing behaviour. Two informants revealed some occasional rudeness and hostility from colleagues during seeking knowledge.

It was also revealed that attitude to knowledge sharing was hindered by misperceptions. The misperception that knowledge sharing was a one man's activity rather than being perceived as everybody's responsibility seemed apparent. Some interviewees remarked, "we don't have a Public Relations Officer (PRO) to disseminate knowledge'. There is need for Monitoring and Evaluation Officer (M\&E) to help in knowledge sharing". With this misperception, some employees did not believe it was their responsibility to share knowledge. One would therefore infer that the positive attitude to share knowledge is shaped by the right perception of both the giver and receiver of knowledge.

\subsection{Subjective Norms and Knowledge Sharing in the Public Sector}

In this section, we examine findings relating to how subjective norms shaped knowledge sharing behaviour in the public sector. The findings are organised around norms that shaped knowledge sharing.

The public sector ministries studied nurtured norms which were not aimed at knowledge sharing, though they made the sharing inevitable. One of such norms was frequent formal meetings. All interviewees indicated that weekly and monthly meetings imposed on them an obligation to attend and exchange ideas. "we meet weekly to review the previous week's performance. My colleagues meet monthly for strategic planning and consideration of field reports". While frequent meetings were not deliberately intended to facilitate knowledge sharing, they formed part of the public sector norms in which knowledge sharing behaviour was reflected. Informants revealed that there was active participation in the meetings. Half of the interviewees revealed that they shared their views freely in these meetings. Yet, they could not ascertain why they shared and whether their shared knowledge was put to the right purpose.

The other well pronounced subjective norm related to job rotation in which some workers in the studied ministries were often transferred to departments within the same ministry, or to other ministries. An informant indicated, "I joined the public sector as a junior officer in the ministry of public sector. I have been transferred recently to the ministry of Justice". Rotated workers encountered new experiences; knowledge networks useful for knowledge sharing. While job rotation stimulated knowledge sharing behaviour it was undertaken for other reasons. Managers in the departments responsible for job rotations indicated that rotations targeted some employees who had been promoted to fill vacancies in other departments. Informants revealed other reasons such as transfer of a problematic employee to a remote department or ministry, or transfer of a worker to a ministry perceived as 'lucrative'. Moreover, job rotation targeted employees below Heads of units that performed similar jobs. In this regard, some interviewees remarked, "I have worked in this department for ten years now. If am transferred to another department it may take me a year to learn". Two other interviewees 
indicated that they had worked at the department for over 20 years and had never been rotated. So, the likelihood that employee rotation imposed social pressures to share knowledge is debatable.

\subsection{Perceived Behaviour Control and Knowledge Sharing in the Public Sector}

Employees in the public sector studied had control over their knowledge. Even when they were sponsored for training, they still had power to decide whether or not to share their knowledge. For example, two informants indicated that, "we encourage people to make presentations after the training but most of them don't want to share. We have arranged meetings for people to share their knowledge but they don't turn up". This perceived behaviour stems from the fact that training guidelines as enshrined in the standing orders did not spell out clear and enforceable procedures relating to knowledge sharing.

To some extent, however, formalization of systems and procedures weakened individual perceived behaviour control. Employees who participated in those tasks were required to share knowledge with team members. It was reported that employees who participated in special projects, assignments and field activities submitted reports to their supervisors in the department. The senior management teams discussed policy issues before forwarding such matters to the top. Such highly formalised environment imposed an obligation on the participating employees to share knowledge and so their behaviour control was to some extent limited.

Much as employees had the ability for behaviour control over knowledge sharing, the resources and incentives for sharing were inadequate. A number of interviewees indicated that the working environment did not motivate them to share knowledge. One informant revealed, "there is no designated place for break tea or lunch. We sit in our offices from morning to evening with only one-hour lunch break. We need staff rooms for health break and informal discussions". Moreover, the ICT infrastructure was not adequate as reported by a number of informants. An informant remarked, "We have always requested for an intranet as a ministry to share information. We need an organizational portal for knowledge sharing". Without this environment, it meant that employees had to physically meet for knowledge sharing instead of using online platforms.

The findings have revealed a number of insights relating to employee attitude towards knowledge sharing, subjective norms that impact on knowledge sharing behaviour, and the perceived behavioural control. The next section is about the discussion of the findings. We attempt to shed light on the practical implications of the findings.

\section{Discussion and Practical Implications}

While workers' attitude to share knowledge in the public sector existed, we notice that the highly formalised environment shaped such attitudes. Knowledge sharing occurred during formal meetings, planning sessions and task related discussions. Yet, even in such a formalised environment, some workers harboured negative attitude to knowledge sharing. Some public sector workers justified knowledge hoarding as a tool to gain and maintain competitive advantage. Previous studies have indicated that employees often feel they are giving away power if they share knowledge (Caruso, 2017) especially in the absence of knowledge sharing incentives (Wang and Noe, 2010). Previous studies especially by Heo and Toomey (2016) also revealed that persuading employees to share their knowledge was challenging because their inherent interests differed. In the same vein, Shanab and Shehabat (2018) studied the perceived behaviour control of public sector employees towards knowledge sharing behaviour and concluded that in the absence of relevant policies and incentives, employees resisted knowledge sharing based on their interest. While we do not subscribe to this practice of knowledge hoarding, bearing in mind that knowledge gains value when it is shared and applied, we are concerned about this negative attitude towards knowledge sharing. However, we are mindful of the fact that asking employees to simply share their knowledge without giving them some incentives is counter-productive. Even when such knowledge has been acquired using organizational resources, it is important that employees are given monetary and non-monetary incentives to share knowledge.

The findings in respect of attitude to knowledge sharing reveal instances when knowledge sharing behaviour was triggered by knowledge seekers. Quite often employees contacted their peers and supervisors on how they were required to undertake certain activities. The theory of planned behaviour has unfortunately focused on attitude of knowledge givers and disregarded the attitude of knowledge seekers. Previous studies have also ignored knowledge seekers' attitudes (Yang, 2008, Safa and Solms, 2016; Howe and Krosnick, 2017). To the best 
of our knowledge, available studies on the subject focused on knowledge seeking in information systems research projects (Sutanto and Jiang, 2013), which is outside the scope of the current study.

The Findings have indicated that employees' behaviour to share knowledge was shaped by the perceived approval by colleagues. Such approval was received during weekly and monthly meetings. There were also some practices such as job rotation which impacted on subjective norms. Job rotation was conducted for reasons beyond knowledge sharing enhancement. Thus, employee rotation was reported as being of little significance in imposing social pressures on the public sector workers to share knowledge. This finding is consistent with previous studies which reflect authors' mixed feelings about job rotation. While such rotation is common among the less performing employees, it can lead to rotated employees gaining more knowledge at their new organisation than actually sharing what they have (Kampkötter, Harbring and Sliwka, 2018). Moreover, when employees are assigned new tasks, their previous knowledge may not be relevant to the current job needs which affects sharing behaviour (Hakenes and Katolnik, 2017). Although the findings of the current and previous studies tend to agree that job rotation does not drive knowledge sharing behaviour, we believe that the rotated employee moves to the new work environment with both tacit and explicit knowledge. On the basis of our findings and previous research, we strongly believe that job rotation may not be a useful component of social norms to drive knowledge sharing intentions. Moreover, some highly specialized jobs such as Legal practice, auditing, Information and Communication Technology (ICT), records and archives management were not rotated.

Although formal meetings were regular and participatory, such meetings imposed an obligation on employees to attend and exchange ideas as part of the organizational norms. Much as these norms were not deliberately nurtured to enhance knowledge sharing, we believe they facilitated knowledge transfer during meetings. Moreover, knowledge sharing activities in government institutions include workshops and meetings (Sensuse, Cahyaningsih and Wibowo, 2015), and brainstorming sessions, using policy documents and reports (Aerts and Haezendonck, 2017; Shanab and Shehabat, 2018). However, we did not find evidence of visible informal meetings which have been found to enhance socialization and fusion of tacit knowledge. Formal meetings should be maintained in governments to facilitate group discussions, brainstorming and exchange of tacit and explicit knowledge. Informal gatherings should be promoted to enhance sharing of tacit knowledge.

Findings revealed that formal work teams imposed social pressures to share knowledge. All interviewees revealed that they often worked in teams. Unfortunately, senior members in such teams dominated discussions. This finding is consistent with previous research by Rushmer, Hunter and Steven (2014) who investigated knowledge sharing in teams and concluded that workshop discussions did not work when dominated by particular individuals and groups. However, earlier researchers (Zhang and Fai Ng, 2012) studied knowledge sharing behaviour among construction teams in Hong Kong and concluded that work teams caused pressure on team members to share knowledge. They, however, noted that such knowledge sharing behaviour depended on antecedents such as provision of rules of the game, error tolerance and provision of team incentives all of which apply in the current study.

The study reveals that some social pressures emanated from Communities of Practice (CoP). The common CoP were among lawyers, management specialists and professional teachers. Some minority CoP such as accountants, engineers, ICT specialists also existed. Previous research has indicated that knowledge sharing behaviour was enhanced in CoP amidst strong support systems from management (Jeon, Kim and Koh, 2011). Other scholars such as Schofield, et al (2018) revealed that some members of CoP sought to enhance their own knowledge as well as strengthen relationships among professional colleagues through the knowledge sharing behaviour. The knowledge sharing behaviour manifested itself during and after the meetings, by use of phone numbers and e-mail. These studies focused on knowledge sharing among CoP. The surprising finding however is that minority CoP in the current study felt that they did not benefit from the knowledge of dominant large CoP such as lawyers and teachers. Inter-CoP collaboration was missing across the three cases. We did not venture deep into this missing link as it was outside the scope of the study. But we believe that future scholars may pick interest in this aspect.

The study has demonstrated that employees' ability and control over knowledge sharing was affected by inadequate organisational resources and incentives. Organizational resources are usually provided through support from management. Previous studies by Wang and Noe (2010) indicated that management support enhanced employee knowledge sharing, the absence of which affected the sharing behaviour. Other studies 
have identified factors such as steep structure and leadership that pose threats to knowledge sharing, compensation and culture (Amayah, 2013; Henttonen, Kianto and Ritala, 2016). A common denominator in all these studies is the key role of management in removing negative perceived behavioural controls to enhance knowledge sharing in the public sector. Our findings in this case agree with previous research that perceived behavioural control can diminish if management creates a flexible environment for knowledge sharing behaviour.

In light of the findings and the preceding discussion, we propose a knowledge sharing model for the public sector. The model attempts to highlight key constructs and dimensions critical to knowledge sharing behaviour in the public sector.

Kge sharing antecedents Organisational factors Kge sharing behaviour

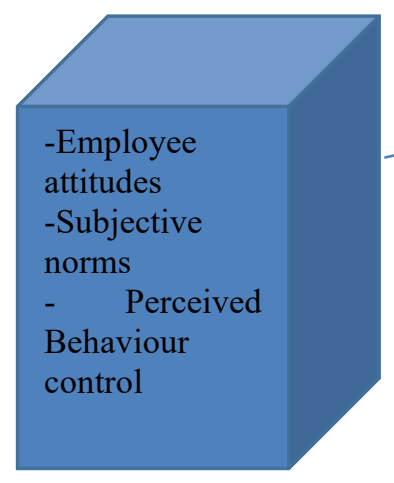

A

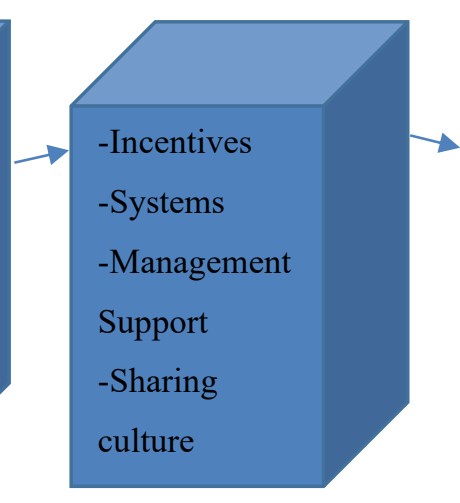

B

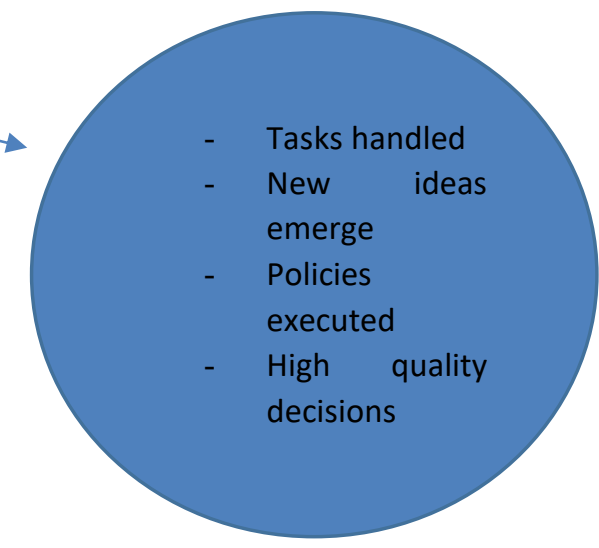

C

Figure 1: Knowledge Sharing Model

The discussion has been guided by the three antecedents of knowledge sharing behaviour reflected in box $A$. These are; employee attitudes to share; subjective norms and perceived approval by others to share knowledge; and lastly, perceived behavioural control. While these antecedents shape the knowledge sharing behaviour in the public sector, they are not self-sufficient. The need for incentives, appropriate systems, management support and sharing culture is critical as indicated in box B. Incentives refer to the combination of various inducements offered to the public sector workers as motivation for them to share knowledge. Such inducements can be monetary or non-monetary. Systems refer to structured practices that position workers to share knowledge with ease. Such systems include formal and informal meetings, teamwork, and staff baraza. Management support relates to any action taken by top management to facilitate knowledge sharing. Such actions include establishment of knowledge sharing policies and creation of knowledge sharing platforms such as social media. In order for knowledge sharing to be effective, antecedents of knowledge sharing and organisational factors should act in concert so as to facilitate solving of task related problems, generating new ideas, designing and executing good policies, as well as making high quality decisions.

\section{Conclusion}

This study was undertaken to examine the antecedents of knowledge sharing behaviour in the public sector. The study has revealed three key antecedents namely; employee attitude to share knowledge, subjective norms, and perceived behavioural control. The study further reveals two surprising findings namely; the recognition of the attitudes of knowledge seekers which have been ignored by previous researchers and collaborations among communities of practice. In the former, the study showed that the knowledge giver's belief that employees seeking knowledge will put it to good use motivated knowledge sharing. Additionally, the knowledge giver's attitude to share was also shaped by how they were approached and respected by the knowledge seekers. In the latter, minority CoP felt sidelined by the large and influential communities of practice thereby limiting knowledge sharing among inter- communities of practice. In light of the revealed antecedents and other key findings, we strongly believe that the research question was answered. 


\subsection{Recommendations and Areas for Future Research}

The study revealed that most employees have negative attitude towards knowledge sharing behaviour. Moreover, it was alleged that some knowledge givers in the public sector were rude to colleagues who sought knowledge from them. While we recommend that employees are given monetary and non-monetary incentives to share knowledge, future researchers should investigate further the kind of incentives likely to enhance knowledge sharing attitudes in the public sector.

Much as the study focused on attitudes towards knowledge sharing behaviour of knowledge givers in the sector, it was discovered that the attitude of knowledge seekers played a role in knowledge sharing. Future studies should investigate how the knowledge seeker behaviour affects the givers attitude to share knowledge.

While we thought that job rotation was useful in enabling knowledge sharing in the public sector, findings and previous studies proved the contrary. It is recommended that the public sector conducts regular job rotations purposely to enhance knowledge sharing.

Highly formalised structures stifled knowledge sharing behaviour. The study recommends establishment of an environment to support informal interactions. Such environment would create employee hubs, online platforms such as social media and knowledge bases, as well as knowledge directories, expert locators and repositories. While Communities of Practice (COP) in teams played a key role in knowledge sharing behaviour, the study did not venture deep into inter-CoP collaboration. Future scholars may pick interest in it this aspect to ascertain how collaborations between communities of practice in a single organizational setting affected knowledge sharing behaviour.

The importance of management support stood out as one of the organisational factors shaping knowledge sharing behaviour. The current study did not venture into the nature of support required as this was outside the scope of the study. We recommend that future researchers should investigate the nature of management support required to enhance knowledge sharing behaviour.

The proposed knowledge sharing model can be tested in studies from different contexts to ascertain its efficacy in settings beyond the public sector.

\subsection{Limitations of the study}

Limitations of this study are two-fold and relate to sample size and design. The public sector in Uganda is bigger than three ministries we studied. The 19 interviewees conducted might be perceived as small. However, we carefully and purposively selected informants on the basis of their wealth experience. Moreover, the purpose of this exploratory study was to help generate deeper insights relating to antecedents of knowledge sharing behaviour in the public sector within a natural setting (Yin, 2011). We relied on the qualitative design well knowing that the purpose of this study was not to generalize the findings (Creswell, 2014) but to reveal a contextualized detail of the phenomenon.

\section{References}

Aerts, G., and Haezendonck, E., 2017. Development and application of an inter-organizational PPP knowledge transfer effectiveness model for knowledge sourced in public sector organizations. American Journal of Industrial and Business Management, [e-journal], 7, 671-710. DOI: 10.4236/ajibm.2017.75050.

Ajzen, I., 1985. From intentions to actions: a theory of planned behaviour. In: J. Kuhl and J. Beckmann, eds., Action control: from cognition to behaviour. Heidelberg: Springer-Verlag.

Ajzen, I., 1991. The theory of planned behaviour. Organizational Behaviour and Human Decision Processes 50(2), pp. 179211. [e-journal]. Available at https://scholar.google.com/scholar?hl=en\&as sdt=0\%2C5\&q=Ajzen\%2C+1.\%2C+1991.+The+theory+of+planned+beha viour.+Organizational+Behaviour+and+Human+Decision+Processes+\&btnG=: [Accessed 6 December 2020].

Aldiabat, K.M. and Navenec, C., 2018. Data saturation: the mysterious step in grounded theory methodology. The qualitative report, [e-journal], 23(1), pp. 245-261. [Accessed 5 May 2019).

Amayah, A.T., 2013. Determinants of knowledge sharing in a public sector organization. Journal of knowledge management, 17(3), pp.454-471. DOI: https://doi.org/10.1108/JKM-11-2012-0369

Caruso, S.J., 2017. A foundation for understanding knowledge sharing: organizational culture, informal workplace learning, performance support, and knowledge management. Contemporary Issues in Education Research, [e-journal],10(1), pp. 45-52. [Accessed 14 July 2019]. 
Castaneda, D. I., Fernández Ríos, M., and Durán, W. F., 2016. Determinants of knowledge-sharing intention and knowledgesharing behavior in a public organization. Knowledge Management \& E-Learning, [e-journal], 8(2), pp. 372-386. [Accessed 16 July 2019].

Castleberry, A. and Nolen, A., 2018. Thematic analysis of qualitative research data: Is it as easy as it sounds? Currents in Pharmacy Teaching and Learning, [e-journal], 10(6), pp. 807-815. DOI: 10.1016/j.cptl.2018.03.019.

Chen, I. Y. L., Chen, N.S., and Kinshuk., 2009. Examining the factors influencing participants' knowledge sharing behavior in virtual learning communities. Educational Technology and Society, [e-journal],12 (1), pp. 134-148. [Accessed 12 August 2019].

Clarke, C., 2009. Can social research paradigms justify the diversity of approaches to social life cycle assessment? International Journal of Life Cycle Assessment, [e-journal], 23, pp.464-480. [Accessed 10 June 2019].

Cong, X. and Pandya, K.V., 2003. Issues of knowledge management in the public sector. Electronic Journal of Knowledge Management, [e-journal],1(2), pp. 25-33. [Accessed 10 September, 2019].

Creswell, J.W., 2014. Research design: Qualitative, quantitative, and mixed methods approaches. $3^{\text {rd }}$ Ed. Los Angeles, Sage.

Erlingsson, C., and Brysiewicz, P., 2017. A hands-on guide to doing content analysis. African Journal of Emergency Medicine, [e-journal],7(3), pp. 93-99. DOI: 10.1016/j.afjem.2017.08.001.

Francis, J.J., Johnston, M., Robertson, C., Glidewell, Entwistle, V., Eccles, M.P., \& Grimshaw, J.M., 2010. What is an adequate sample size? Operationalizing data saturation for theory-based interview studies. Psychology and Health, [e-journal], 25(10), pp. 1229-1245. DOI: 10.1080/08870440903194015.

Furlich, S.A., 2016. Understanding employee motivation through managerial communication using expectancy-valence theory. Journal of Integrated Social Sciences, [e-journal], 6(1), pp.17-37. [Accessed 11 June 2019].

Hajli, N. and Lin, X., 2016. Exploring the security of information sharing on social networking sites: the role of perceived control of information. Journal of Business Ethics [e-journal], 133(1), pp.111-123. https://doi 10.1007/s551-014-2346x. 133(1), pp. 111-123.

Hakenes, H. and Katolnik, S., 2017. On the incentive effects of job rotation. European Economic Review, [e-journal], 98, pp.424-441.DOI: 10.1016/j.euroecorev.2017.07.003.

Halcomb, E.J., and Davidson, P.M., 2006. Is verbatim transcription of interview data always necessary? Applied Nursing Research, [e-journal], 19(1) pp. 38-42. DOI: 10.1016/j.apnr.2005.06.001.

Henttonen, K., Kianto, A., Ritala, P., 2016. Knowledge sharing and individual work performance: an empirical study of a public sector organisation, Journal of Knowledge Management, [e-journal], 20(4), pp.749-768. DOI: 10.1108/JKM-102015-0414.

Heo, M, and Toomey, N., 2016. Supporting sustained willingness to share knowledge with visual Feedback. Computers in Human Behavior, [e-journal], 54(c), pp.388-396. DOI:10.1016/J.chb.2015.08.034.

Hew, K.F. and Hara, N., 2007. Knowledge sharing in online environments: a qualitative case study. Journal of the American Society for Information Science and Technology, [e-journal], 58(14), pp.2310-2324. https://doi.org/10.1002/asi.20698.

Howe, L.C. and Krosnick, J.A., 2017. Attitude Strength. Annual Review Psychology, [e-journal] 68(1), , pp. 327-51. doi: 10.1146/annurev-psych-122414-033600.

Hwang, Y., (2012). Understanding moderating effects of collectivist cultural orientation on the knowledge sharing attitude by email. Computers in Human Behavior, [e-journal], 28(6), pp.2169-2174. [Accessed 12 June 2019].

Jeon, S., Kim, Y.G. and Koh, J., 2011. An integrative model for knowledge sharing in communities-of-practice. Journal of Knowledge Management, [e-journal], 15(2), pp.251-269. DOI: 10.1108/13673271111119682.

Kampkötter, P, Harbring, C. and Sliwka, D., 2018. Job rotation and employee performance - evidence from a longitudinal study in the financial services industry, The International Journal of Human Resource Management, [e-journal], 29(10), pp.1709-1735. https://doi.org/10.1080/09585192.2016.1209227.

Kalani, E. and Kamrani, E., 2017. Pathology of barriers to sharing knowledge in project management and ranking them by AHP method. Journal of Human Resource and Sustainability Studies, [e-journal], 5(1), pp.68-74. https://doi.org/10.4236/jhrss.2017.51007.

Kuo, F. Y. and Young, M., 2008. Predicting knowledge sharing practices through intention: A test of competing models. Computers in Human Behavior, [e-journal], 24(6), pp.2697-2722. http://dx.doi.org/10.1016/j.chb.2008.03.015.

Liu, Y., and DeFrank, R.S., 2013. Self-interest and knowledge-sharing intentions: the impact of transformational leadership climate and HR practices. The International Journal of Human Resource Management, [e-journal], 24(6), pp.11511164. https://doi.org/10.1080/09585192.2012.709186.

Nguyen, T. M., Nham, P.T., Hoang, V., 2019. The theory of planned behavior and knowledge sharing: A systematic review and meta-analytic structural equation modelling. Journal of Information and Knowledge Management Systems, [ejournal], 49(1), pp.76-94. DOI:10.1108/VJIKMS-10-2018-0086.

OECD., 2015. OECD and post 2015 Reflections: Policy dialogue, knowledge sharing and engaging in mutual learning. [epaper], Element 9, Paper 1. Available at: http://www.oecd.org/knowledge-sharing-alliance/OECD-Post-2015_PolicyDialogue-Knowledge-Sharing-and-Engaging-in-mutual-learning.pdf. [Accessed 13 August 2019].

Moghavvemi, S., Sharabati, M, Paramanathan, T. and Rahin, N.M., 2017. The impact of perceived enjoyment, perceived reciprocal benefits and knowledge power on students' knowledge sharing through Facebook, The International Journal of Management Education, [e-journal], 15(1), pp. 1-12. https://doi.org/10.1016/j.ijme.2016.11.002. 
Parka, C.H., Song, J.H., Lim, D.H. and Kim, J.W., 2014. The influences of openness to change, knowledge sharing intention and knowledge creation practice on employees' creativity in the Korean public sector context. Human Resource Development International, [e-journal],17(2), pp.203-221. https://doi.org/10.1080/13678868.2013.876256.

Petty J, Jarvis J, and Thomas, R., 2018. Core story creation: analyzing narratives to construct stories for learning. Nurse Researcher, [e-journal], 25(4), pp.47-51. doi: 10.7748/nr.2018.e1533.

Punniyamoorthy, M., and Asumptha, J. A., 2019. A study on knowledge sharing behavior among academicians in India. Knowledge Management. \& E-Learning, [e-journal],11(1), pp. 95-113. http://doi.org/10.34105/j.kmel.2019.11.006.

Rushmer, R.K, Hunter, D.J., and Steven, A., 2014. Using interactive workshops to prompt knowledge exchange: a realist evaluation of a knowledge to action initiative. Public Health, [e-journal], 128(6), pp.55-60. doi: 10.1016/j.puhe.2014.03.012.

Safa, N.S and Solms, R.V., 2016. An information security knowledge sharing model in organizations. Computers in Human Behavior, [e-journal], 57, pp.442-451. https://doi.org/10.1016/j.chb.2015.12.037.

Schofield, K, Analoui, B.D., Brooks, J. and Husain, S.F., 2018. Competitive communities of practice, knowledge sharing, and Machiavellian participation: a case study. International Journal of Training and Development 22(3), pp. 1360-3736.

Sensuse, D.I., Cahyaningsih, E. and Wibowo, W.C., 2015. Identifying knowledge management process of Indonesian government human capital management using analytical hierarchy process and pearson correlation analysis. Procedia Computer Science, (72), pp.233-243. https://doi.org/10.1016/j.procs.2015.12.136.

Shanab, E, and Shehabat, I., 2018. The influence of knowledge management practices on e-government success: A proposed framework tested. Transforming government: People, Process and Policy, [e-journal],12(3/4), pp.286-308. DOI: 10.1108/TG-02-2018-0016.

Sutanto, J. and Jiang, Q., 2013. Knowledge seekers' and contributors' reactions to recommendation mechanisms in knowledge management systems. Information \& Management, [e-journal], 50(5), pp.258-263. DOI.10.1016/j.im.2012.11.004. [Accessed 5 May 2019].

Turyahikayo, E., 2018. Bureaucratic rigidity, risk aversion and knowledge generation and utilization in the public sector: Reality or illusion? Management and Organizational Studies, 5(3), pp.9-16, Doi:10.5430/mos.v5n3p9.

Wamitu, S.N. 2016. Functional boundaries as a tacit knowledge sharing factor and its effect on public sector performance in Kenya. Open Journal of Business and Management, [e-journal], 4(2), pp.225-237. DOI: 10.4236/ojbm.2016.42024.

Wang, S. and Noe, R.A., 2010. Knowledge sharing: A review and directions for future research. Human Resource Management Review, [e-journal], 20(2), pp.115-131. https://doi.org/10.1016/j.hrmr.2009.10.001.

Yang, J., 2008. Individual attitudes and organisational knowledge sharing, Tourism Management, [e-journal], 29(2), pp.345353. https://doi.org/10.1080/02642060902793490.

Yean, T.F. Johari, J. and Sukery, A.F.M., 2015. The influence of attitude, subjective norms, and perceived behavioural control on intention to return to work: a case of socso's insured employees. Kajian Malaysia, [e-journal], 33(1), pp.141-154. Available at: https://www.researchgate.net/profile/Tan_Fee_Yean/publication/305432662. [Accessed 8 June 2019].

Yin, R.K., 2011. Qualitative Research from Start to Finish. New York: Guilford Press.

Zhang, P. and Fai Ng, F., 2012. Attitude toward knowledge sharing in construction teams. Industrial Management \& Data Systems, [e-journal], 112(9), pp.1326-1347.DOI: 10.1108/02635571211278956. 